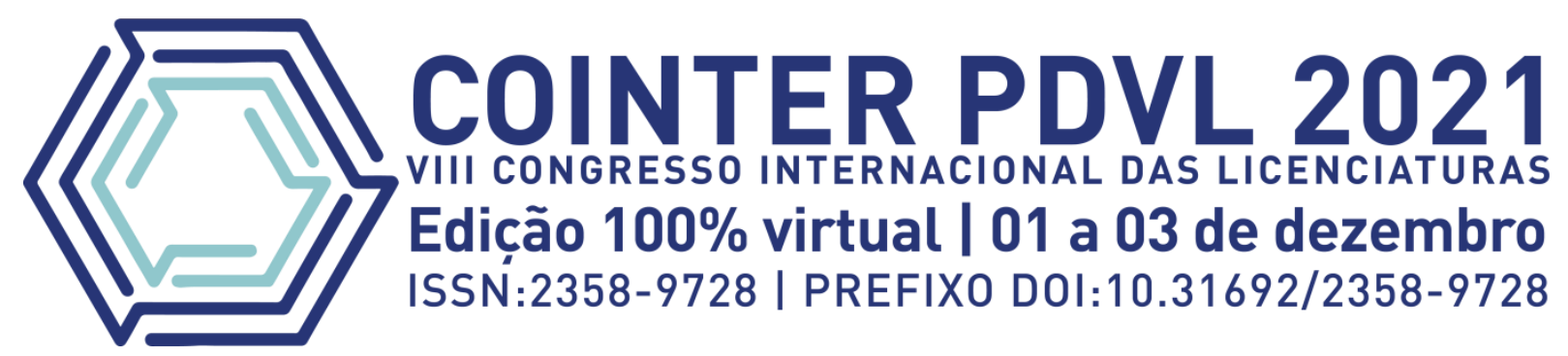

\title{
A IMPORTÂNCIA DA CONSTRUÇÃO DO PROJETO POLÍTICO PEDAGÓGICO: MISSÃO, VISÃO E VALORES E SUA FLEXIBILIDADE NA PRÁTICA PROFISSIONAL
}

\author{
LA IMPORTANCIA DE LA CONSTRUCCIÓN DEL PROYECTO POLÍTICO \\ PEDAGÓGICO: MISIÓN, VISIÓN Y VALORES Y SU FLEXIBILIDAD EN LA \\ PRÁCTICA PROFESIONAL
}

\section{THE IMPORTANCE OF CONSTRUCTION OF THE PEDAGOGICAL POLITICAL PROJECT: MISSION, VISION AND VALUES AND THEIR FLEXIBILITY IN PROFESSIONAL PRACTICE}

\begin{abstract}
Apresentação: Comunicação Oral
Mayane Djanira dos Santos ${ }^{1}$; Rute Israeli Rocha Pereira ${ }^{2}$; Wilton José Leal da Costa ${ }^{3}$ DOI: https://doi.org/10.31692/2526-7701.VIIICOINTERPDVL.0027

RESUMO

Essa pesquisa buscou como objetivo entender os caminhos percorridos para a construção do Projeto Político Pedagógico - PPP na Escola Municipal de Referência em Ensino Fundamental Dom Malan, localizada no município de Salgueiro - PE. As três dimensões, missão, visão e valores representam a organização desempenhada em uma instituição, descrevendo a parte do Planejamento Estratégico em que o local define o que espera se realizar em um determinado tempo no contexto organizacional, e constituem parte primordial do Planejamento Estratégico associando a convicções e o respeito do que se considera importante para a realização de objetivos, visto que, as dimensões contribuem de forma significativa para a constituição do Projeto Político Pedagógico. Aplicou-se na escola campo um questionário tendo como público alvo o núcleo escolar responsável pela a construção do PPP, visando entender como se é colocado em prática pelos os docentes nas suas diversas funções na unidade escolar; e estudar a importância que esse documento desempenha na atuação profissional. Mediante os resultados obtidos, entende-se que a introdução do Projeto Político Pedagógico - PPP na escola deve está lado a lado com o trabalho em conjunto para que as propostas consolidadas apresentem a devida fundamentação no desenvolvimento das práticas. Portanto, o Projeto Político

\footnotetext{
${ }^{1}$ Ciências Biológicas, FACHUSC, mayanesantos2017@ hotmail.com

${ }^{2}$ Ciências Biológicas, FACHUSC, ruteisraeli451@gmail.com

${ }^{3}$ Especialização em Ensino de Biologia e química, EREM Dom Malan, wiltonleal01@gmail.com
} 


\title{
A IMPORTÂNCIA DA CONSTRUC̣̃̃o DO PROJETO POLÍTICO
}

Pedagógico - PPP é um documento necessário no ambiente escolar, o mesmo expõe todos os componentes relacionados à estrutura geral da instituição, envolvendo todas as informações necessárias que estejam relacionadas à escola e a todos os seus membros. A ideia não é a criação de seres que criticam sem saber o que, ou que meramente sejam máquinas de produção, já que a predisposição de argumentar e saber lutar pelos princípios individuais e coletivos inicia-se na atuação escolar.

Palavras-Chave: Projeto Político Pedagógico, Missão, visão e valores, Escola.

\section{RESUMEN}

Esta investigación tuvo como objetivo conocer los caminos tomados para la construcción del Proyecto Político Pedagógico - PPP en la Escuela Municipal de Referencia Dom Malan en Educación Primaria, ubicada en el municipio de Salgueiro - PE. Las tres dimensiones, misión, visión y valores representan la organización realizada en una institución describiendo la parte de la Planificación Estratégica en la que la ubicación define lo que se espera hacer en un momento dado en el contexto organizacional, y constituyen una parte primordial de la Planificación Estratégica asociándose a las convicciones y el respeto por lo que se considera importante para el logro de los objetivos, ya que, las dimensiones contribuyen significativamente a la constitución del Proyecto Político Pedagógico. Se aplicó un cuestionario en la escuela de campo con el público objetivo del núcleo escolar responsable de la construcción del PPP con el fin de comprender cómo lo ponen en práctica los docentes en sus diversas funciones en la unidad escolar; y estudiar la importancia que este documento juega en el desempeño profesional. Con base en los resultados obtenidos, se entiende que la implantación del Proyecto Político Pedagógico - PPP en la escuela debe ir de la mano del trabajo conjunto para que las propuestas consolidadas presenten la base adecuada en el desarrollo de prácticas. Por tanto, el Proyecto Político Pedagógico-PPP es un documento necesario en el ámbito escolar, expone todos los componentes relacionados con la estructura general de la institución, involucrando toda la información necesaria relacionada con la escuela y todos sus integrantes. La idea no es la creación de seres que critican sin saber qué, o que son meras máquinas de producción, ya que la predisposición a argumentar y saber luchar por principios individuales y colectivos parte del desempeño escolar.

Palavras-Chave: Proyecto Político Pedagógico, Misión, Visión y Valores, Escuela.

\begin{abstract}
This research aimed to understand the paths taken for the construction of the Pedagogical Political Project - PPP at the Dom Malan Reference Municipal School in Elementary Education, located in the municipality of Salgueiro - PE. The three dimensions mission, vision and values represent the organization performed in an institution describing the part of the Strategic Planning in which the location defines what is expected to be done at a given time in the organizational context, and constitute a primordial part of the Strategic Planning associating with convictions and respect for what is considered important for the achievement of objectives, since, the dimensions contribute significantly to the constitution of the Pedagogical Political Project. A questionnaire was applied in the field school with the target audience of the school nucleus responsible for the construction of the PPP in order to understand how it is put into practice by the teachers in their various functions in the school unit; and study the importance that this document plays in professional performance. Based on the results obtained, it is understood that the introduction of the Pedagogical Political Project - PPP in the school should go hand in hand with the joint work so that the consolidated proposals present the proper foundation in the development of practices. Therefore, the Pedagogical Political Project-PPP is a necessary document in the school environment; it exposes all the components related to the general structure of the institution, involving all the necessary information related to the school and all its members. The idea is not the creation of beings who criticize without knowing what, or who are merely production machines, since the predisposition to argue and know how to fight for individual and collective principles starts in school performance.
\end{abstract}


Palavras-Chave: Political Pedagogical Project, Mission, Vision and Values, School.

\section{INTRODUÇÃO}

O Projeto Político Pedagógico das instituições são bases sólidas no desenvolvimento de uma gestão democrática. Visto que, por meio dele o gestor da instituição identifica e objetiva a atuação de todos nas resoluções das metas e nas execuções das ações, assumindo assim, o compromisso de por em prática todas as metas que foram planejadas (TRINDADE et al., 2015). Ainda segundo o autor, o PPP não é algo que se é elaborado e logo depois, se é arquivado ou direcionado as autoridades educacionais como evidência do cumprimento dos serviços burocráticos. Ele deve ser criado e, por conseguinte, vivenciado a todo o momento, por todos os envolvidos no processo educativo da escola, colaborando assim para uma escola ativa e democrática.

Segundo Silva (2011), no inicio do século XXI o Brasil possuía uma enorme acúmulo de poder que circulavam em torno da política e da economia, fazendo com quer isso causasse a exclusão e a marginalização das camadas sociais menos desajudadas, dessa forma, a escola não conseguia fechar os olhos na presença desta prática de privilégios. Consequentemente, veio à necessidade da escola em desenvolver o Projeto Político pedagógico - PPP, que estivesse bem estruturado com o desenvolvimento das perspectivas sócio-políticas que a sociedade vivenciava. Á vista disso, este trabalho educativo é um recurso capaz de transpassar os limites do individualismo para adquirir progressos significativos, uma vez que, a partir de uma construção comunitária todos os envolvidos se beneficiarão no processo de forma justa.

Santos (2013), afirma que a elaboração do Projeto Político Pedagógico - PPP requer bastante dos envolvidos nesse processo, já que se faz necessária a articulação das diversas partes que constitui a comunidade escolar. Ainda segundo o autor supracitado, a construção do PPP em muitas escolas não acontece de forma participativa e, por isso, o mesmo acaba não se solidificando, perdendo assim, o seu real sentido que é ser mediador das decisões, já que é ele quem direciona a escola nas resoluções futuras com base na realidade atual, prevendo as ações a curto, médio e longo prazo, mediando diretamente e diariamente nas práticas pedagógicas.

Para que aconteça um funcionamento institucional favorável a todos, o Projeto Político Pedagógico precisa ser desenvolvido de modo coerente, pois, o mesmo servirá de suporte para o desempenho anual da instituição, sendo possível que o mesmo seja sujeito a modificações durante esse período, desempenhado o começo da flexibilidade escolar. Nesse documento deve está incluso todos os dados da escola, seus ideais, histórico, seus contextos sociais, bem como suas vulnerabilidades e suas invulnerabilidades, para que assim possa 


\section{A IMPORTÂNCIA dA CONSTRUC̨ÃO DO PROJETO POLÍTICO}

ocorrer um bom funcionamento institucional (FIGUEIREDO; BOTELHO, 2018).

Desse modo, o Projeto Político Pedagógico - PPP possui três dimensões consideradas indispensáveis na sua criação, à missão, os valores e a visão, são eles quem norteia a instituição nos objetivos que a mesma deseja alcançar. A missão de qualquer instituição é dar sentido as estratégias que a mesma pretende cumprir sem deixar de ser adaptável ao meio a qual faz parte, para assim, poder ser aplicada de acordo com as situações causadas por mudanças culturais, políticas ou até mesmo econômicas. Será por meio dela que a escola poderá prestar suporte para as ações atuais que espelharão no futuro da instituição e no alcance da visão (MACÊDO, 2016). Ainda conforme o autor, a visão da instituição precisa ser amplamente difundida entre os colaboradores da mesma, a fim de que ela seja acessível fazendo com que as ações estratégicas proporcionem a conexão entre os outros elementos de forma não só eficaz, mas também realista. Portanto, é possível afirmar que a visão acompanha a missão, onde a visão focaliza no futuro incentivando e motivando toda a escola, a missão manterá sempre seu foco nas ações do presente, norteando a instituição rumo ao futuro, além de orientar nos objetivos e nos investimentos a serem feitos pela escola. As instituições assim como os seres humanos também precisam possuir princípios e valores que os conduzam nas decisões e nos comportamentos, independente do ambiente externo ao qual se encontra. Neste sentido, os valores morais e éticos precisam ser totalmente respeitados, pois, os valores institucionais são atributos direcionados à execução das atividades cotidiana, e isso possui uma enorme influência na percepção da sociedade.

Neste contexto, buscou-se como objetivo analisar a forma com que o PPP é elaborado e executado na Escola de Referência em Ensino Fundamental Dom Malan, frente aos olhares dos gestores (coordenadores e diretores), além disto, os docentes. Para atingir esse objetivo precisa-se verificar quem efetivamente contribui na construção do PPP; como se é colocado em prática pelos os docentes nas suas diversas funções na unidade escolar; e estudar a importância que esse documento desempenha na atuação profissional.

Como metodologia para identificar a realidade em que se encontra a escola, foi realizada uma pesquisa de campo, com a aplicação de um questionário junto aos docentes, coordenadores, diretores, e demais colaboradores da instituição de ensino, sendo todos atuantes da mesma instituição pública localizada na área urbana central do município de Salgueiro (PE).

Espera-se mostrar como verdadeiramente a instituição faz uso do seu projeto politico pedagógico nas decisões, acerca dos seus profissionais atuantes e o nível de participação da comunidade na escola. 


\section{FUNDAMENTAÇÃO TEÓRICA}

O Projeto Político Pedagógico - PPP, é o principal documento norteador do ambiente escolar, tem o objetivo de orientar o trabalho desenvolvido em todas as situações que nele demostram estar inseridas ou associadas, envolvevendo também partes administrativas, pedagógicas e políticas (GUEDES, 2021).

O Projeto Político Pedagógico- PPP, presente em uma instituição de ensino, presume a ação intencional constituída como um documento democrático e participativo do núcleo escolar. Além de abordar a ação pedagógica, o PPP também aborda a identidade da escola, pois, é a partir desse manuscrito que as atividades docentes são pensadas, planejadas e escritas, possibilitando assim a organização e a efetivação do trabalho do docente. (PAIVA, 2019).

Todo o trabalho da elaboração do Projeto Político Pedagógico - PPP para a constituição escolar, envolve ações fundamentadas nos referenciais teóricos e legais, além de ser o resultado do comprometimento do núcleo que faz parte da sua elaboração, ou seja, os profissionais da educação. Portanto, torna-se necessário uma preocupação com um plano de ensino responsável, ou seja, dos profissionais do ensino, dos gestores, e todos que constituem a comunidade escolar, para dar condições de executar, reformular políticas públicas e fortalecer os estudos e a formação contínua (RODRIGUES, 2018).

Nessa perspectiva, vale ressaltar que o projeto político-pedagógico não deve ser construído sem uma gestão participativa, para que não o torne elemento meramente burocrático, e fechado em si mesmo. Isso porque a gestão democrático-participativa assume condição de peça-chave para dar sentido e criar ações baseadas nos objetivos discutidos com a comunidade escolar e local, e que serão responsáveis pela operacionalização do Projeto Politíco Pedagógico, o empenho dos funcionários é essencial, além de promover um bom trabalho, o clima de hâmonia, companherismo também favorece um ótimo desempenho (GUEDES, 2021).

Um dos principais responsáveis pela escolha das pessoas que vão fazer parte da comunidade escolar, responsável por esse documento, é o gestor escolar, pois, através de medidas criativas e parcerias, ele pode motivar sua equipe para atingir resultados positivos. A missão não é fácil e exige mudanças de grande porte para a gestão de uma escola pública. Mas a escola como fonte de saber, precisa colocar em prática o que há de mais dinâmico e eficiente na falta de recursos materiais e de pessoais (OLIVEIRA et al, 2018).

São poucos os trabalhos que apresentam informações didáticas detalhadas sobre os 


\section{A IMPORTÂNCIA dA CONSTRUC̨ÃO DO PROJETO POLÍTICO}

conceitos de missão, visão e valores. Na sua maioria, as conceituações realizadas são, por vezes, distintas ou podem se constituir por discussões sobre essas temáticas, porém, esses assuntos deveriam estar mais presentes na escrita de trabalhos relacionados ao projeto político pedagógico, pois contribuem significativamente para a soma de informações construtivas sobre os itens acima já citados (FERREIRA, 2016).

O item "missão" faz parte do Planejamento do Projeto Politico Pedagógico, o mesmo define a proposta de contribuir na construção e organização que existe em uma instituição. Portanto, missão representa a organização desempenhada e torna-se importante na definição do documento, é também à medida que proporciona fazer com que a organização dos componentes abodados na sua descrição seja descrita de uma maneira que contribua para desmpenhar um bom trabbalho docente. Além de seu significado no contexto interno da escola, com isso, possui um significado externo, no sentido de que mostra aos membros ecolares o que o ambiente se propõe. (FERREIRA, 2016)

No contexto do item "visão" descreve a parte do Planejamento Estratégico do Projeto Politico Pedagógico, além de definir o que possa vim a se realizar em um determinado tempo, orientando os colaboradores para o futuro, contudo, não se distancia da realidade presente no ambiente (FFERREIRA, 2016). Ainda conforme o autor, o item "valor", enquanto conceito organizacional, é capaz de compor alguns aspectos básicos implícitos no conceito: a dimensão relacional e a hierarquização. Valores, no contexto de organização, que constituem parte primordial do Planejamento do Projeto Politico Pegagógico e referindo-se as convicções que se considera importante para a realização de objetivos propostos, por fornecerem um meio de direção comum para todos os membros educacionais que fazem parte da sua elaboração.

Um dos problemas enfrentados na construção da estrutura missão, visão e valores é a má elaboração dos mesmos, mediante a falta de informações sobre os itens, é possivel afirmar isso, muitas pessoas não têm noção da importância desses tópicos. Além de servi para exemplificar articulações entre os conceitos educacionais, também enfatiza a importância da elaboração e descrição detalhada dos mesmos e, ainda, para evidenciar a atuação destes conceitos na formação da identidade organizacional presente no documento (FERREIRA, 2016).

Os objetivos de uma instituição pública de educação é promover maior indice de qualidade em seu desenvolvimento geral de ensino, nos propósitos e no conjunto dos ideais que norteiam as atividades doss membros que compõem essa instiuição, com isso, os itens de missão, valores e visão, mediante essas informações, é explícito afirmar que, são essencias na construção de um dos documentos mais importantes da escola o Projeto Político Pedagógico - 
PPP (LEAL, 2017).

\section{METODOLOGIA}

A pesquisa foi realizada no município de Salgueiro, o qual está localizado no interior do estado de Pernambuco, na região nordeste do país, há $513 \mathrm{~km}$ da capital estadual Recife (Figura 1). Segundo o IBGE (2020), o município possui uma extensão territorial de 1.678,564 $\mathrm{km}^{2}$, sendo $6,75 \mathrm{~km}^{2}$ em perímetro urbano, tendo sua população estimada em 61.249 habitantes. A área campo de levantamento de dados foi a Escola Municipal de Referência em Ensino Fundamental Dom Malan (figura 2), a mesma, lida com alunos do ensino fundamental dos anos iniciais e finais, sendo que, do $1^{\circ}$ ao $5^{\circ}$ em tempo parcial e do $6^{\circ}$ ao $9^{\circ}$, tempo integral.

Figura 1- Mapa de localização geográfica da área de estudo.

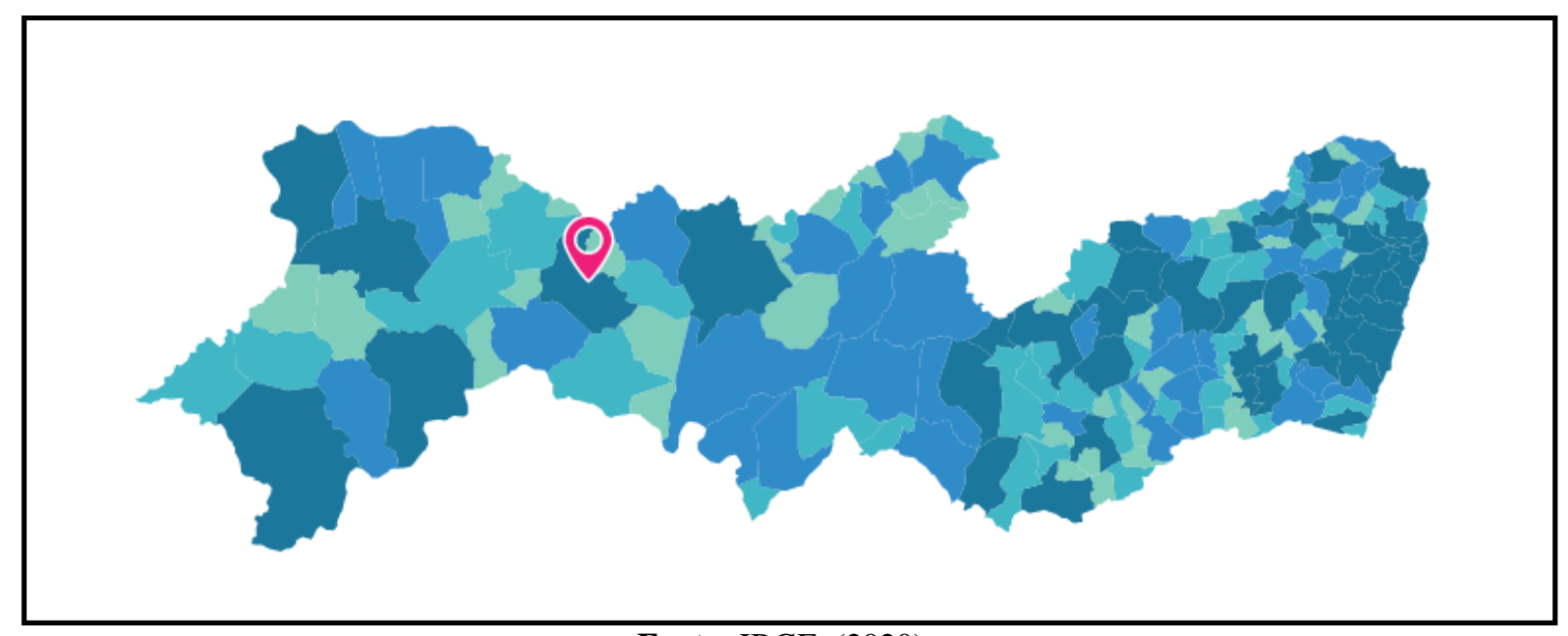

Fonte: IBGE, (2020). 


\section{A IMPORTÂNCIA DA CONSTRUC̨ÃO DO PROJETO POLÍTICO}

A Escola localiza-se na Rua Carlos Soares de Brito S/N - Santo Antônio, do município acima já citado.

Figura 2 - Fachada da escola na qual o questionário foi aplicado.

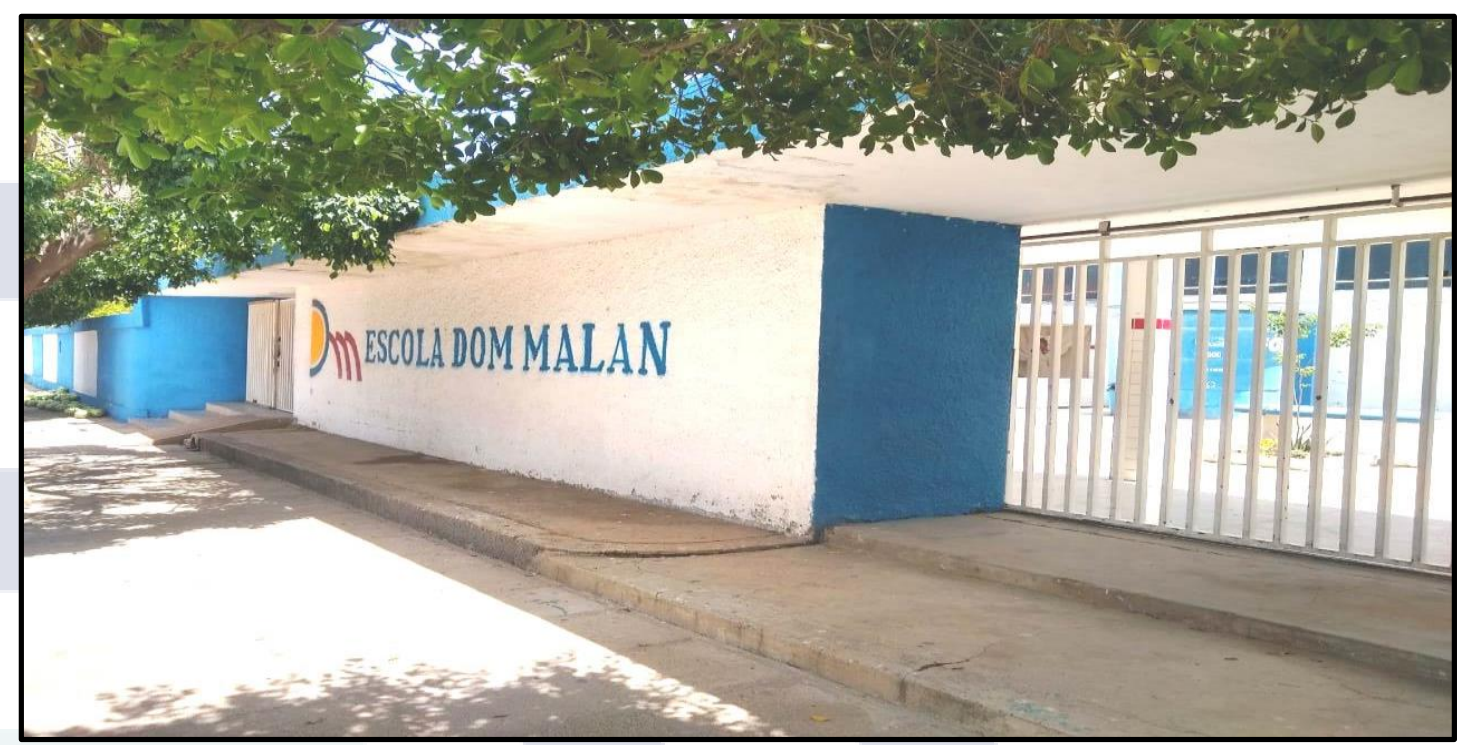

Fonte: Própria (2021).

A metodologia adotada foi qualitativa do tipo pesquisa-ação, onde através do uso de um questionário digital, confeccionado a partir do aplicativo Google Forms, se fez possível a coleta de respostas dos funcionários da Escola EREM Dom Malan da zona urbana de Salgueiro-PE. O questionário foi enviado há vinte participantes através das redes sociais via WhatsApp, garantindo a integridade dos mesmos e dos pesquisadores quanto à disseminação da COVID-19. O questionário foi constituído por 05 questões, tendo como foco principal das perguntas, o conhecimento sobre como é desenvolvido e trabalhado o Projeto Político Pedagógico - PPP na Escola. 


\section{RESULTADOS E DISCUSSÃO}

Diante dos resultados obtidos através dos gráficos, foi possível constatar um baixo retorno do questionário por parte dos funcionários da escola. À analise dos resultados, através dos gráficos, apresenta os dados coletados em termos percentuais, seguindo com a exposição e a análise das cinco questões.

Gráfico 1 - Avaliação dos funcionários da escola.

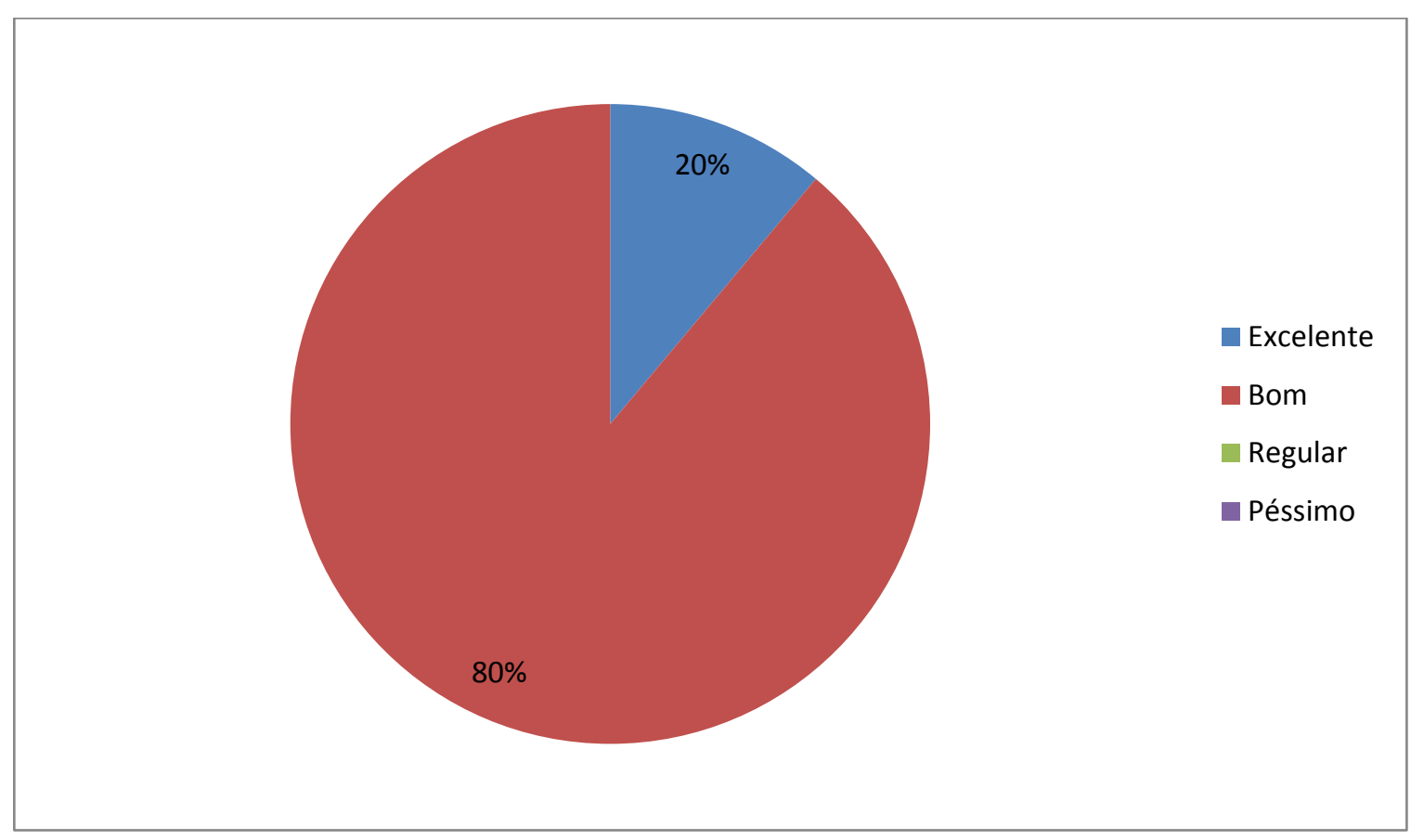

Fonte: Própria (2021).

O gráfico 1 retrata a questão acerca da avaliação dos funcionários sobre a criação do Projeto Político Pedagógico - PPP. Houve uma pequena divergência entre os participantes, já que o retorno obtido das respostas não apresenta grande significância, por não ter atingido o percentual de funcionários desejados.

Com tudo, Trindade (2015) afirma que, uma instituição que possui seu Projeto Político Pedagógico com uma base sólida, adquiriu uma identidade transparente e uma gestão com maior confiança nas suas tomadas de decisões. E, a partir disto, a instituição se faz mais democrática, com atuação mais ativa de toda a comunidade escolar na elaboração e na execução do PPP. 


\section{A IMPORTÂNCIA DA CONSTRUC̨ÃO DO PROJETO POLÍTICO}

Gráfico 2 - Item do PPP de maior dificuldade na elaboração.

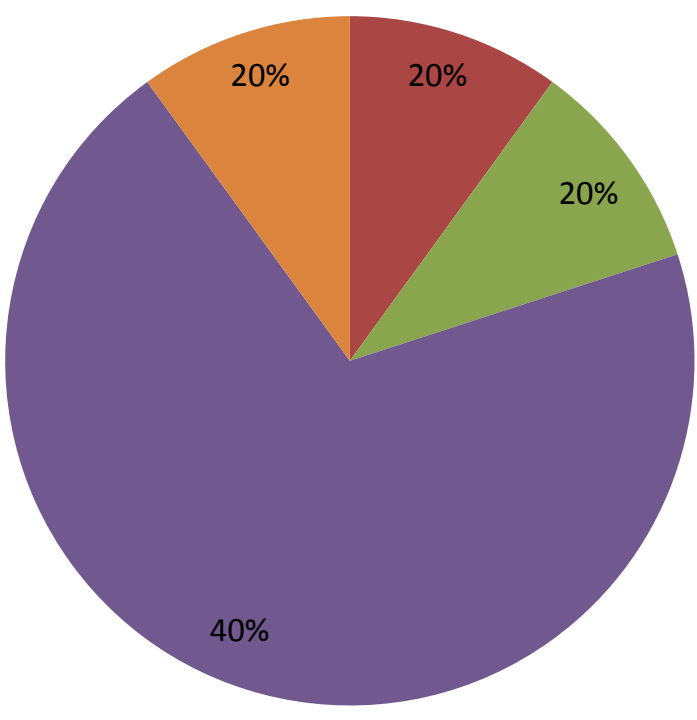

- Identificação

- Visão, Valores e Missão

Estrutura Organizacional

Estrutura Física

Proposta Curricular

- Plano de Ação

Fonte: Própria (2021).

O gráfico 2 retrata o conhecimento acerca dos itens de maior dificuldade na elaboração do Projeto Político Pedagógico - PPP. Destacou-se um elevado nível de diversidade no percentual de respostas apresentadas. A estrutura física foi a mais cogitada como o item de maior dificuldade na elaboração do projeto, pois, as instituições de ensino não possuem recursos financeiros suficientes para a melhoria do ensino e aprendizagem dos alunos no ambiente escolar. Os resultados obtidos no gráfico acima corroboram com Paschoal (2016), onde o mesmo afirma que as escolas públicas são afetadas diretamente pelo sistema, visto que, a estrutura física das escolas interfere diretamente no processo ensino aprendizagem dos alunos que fazem parte dessas instituições e, se faz notória, a falta dessas estruturas básicas, tendo como exemplo, a falta da cobertura das quadras, salas com pouca ventilação, refeitórios com acentos, mas, não para todos, falta de biblioteca, de salas de informática e de laboratórios para que aconteçam as aulas práticas que são de grande relevância na ficção dos conteúdos, tudo isso causam nos alunos desinteresse e desmotivação pela educação. 
Gráfico 3 - O PPP é necessário na instituição.

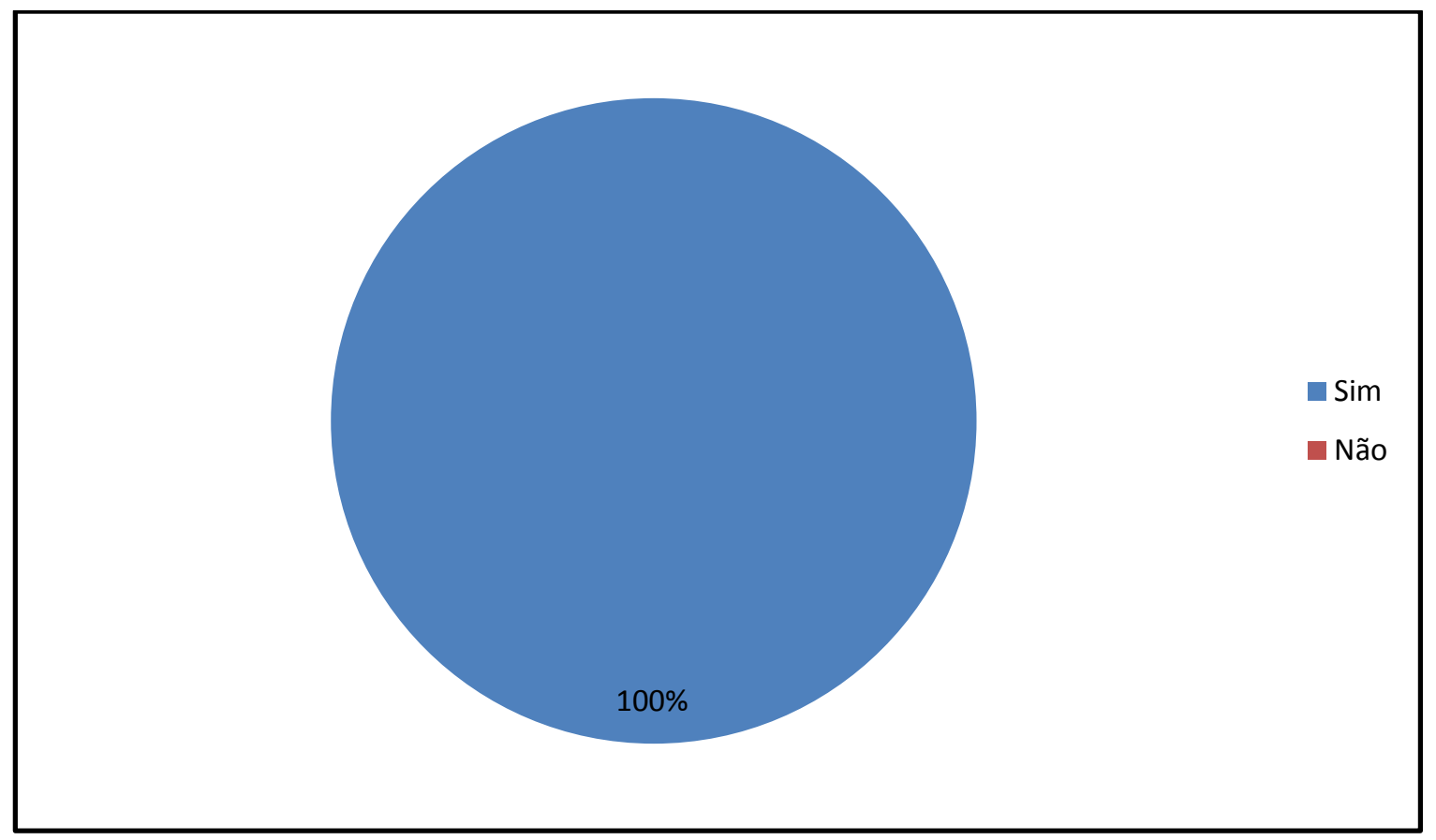

Fonte: Própria (2021).

No gráfico 3 é demonstrado a importância da criação do Projeto Político Pedagógico PPP nas instituições de ensino, pois, o documento elaborado permite a consolidação nas decisões acerca da estrutura funcional do núcleo escolar. Nos dados obtidos é possível constatar que os funcionários têm conhecimento da relevância do mesmo para uma escola mais democrática. Para Figueiredo; Botelho (2018) com uma prática pedagógica harmônica, a instituição consegue alcançar as melhorias almejadas, além de contentar o sistema educacional. Ao se doar verdadeiramente, a escola conseguiu possibilitar a real edificação do conhecimento, formando assim, estudantes mais críticos, conscientes e criativos, que não se permitam somente serem máquinas manipuláveis nas mãos da sociedade. 
Gráfico 4 - Uso do PPP na instituição.

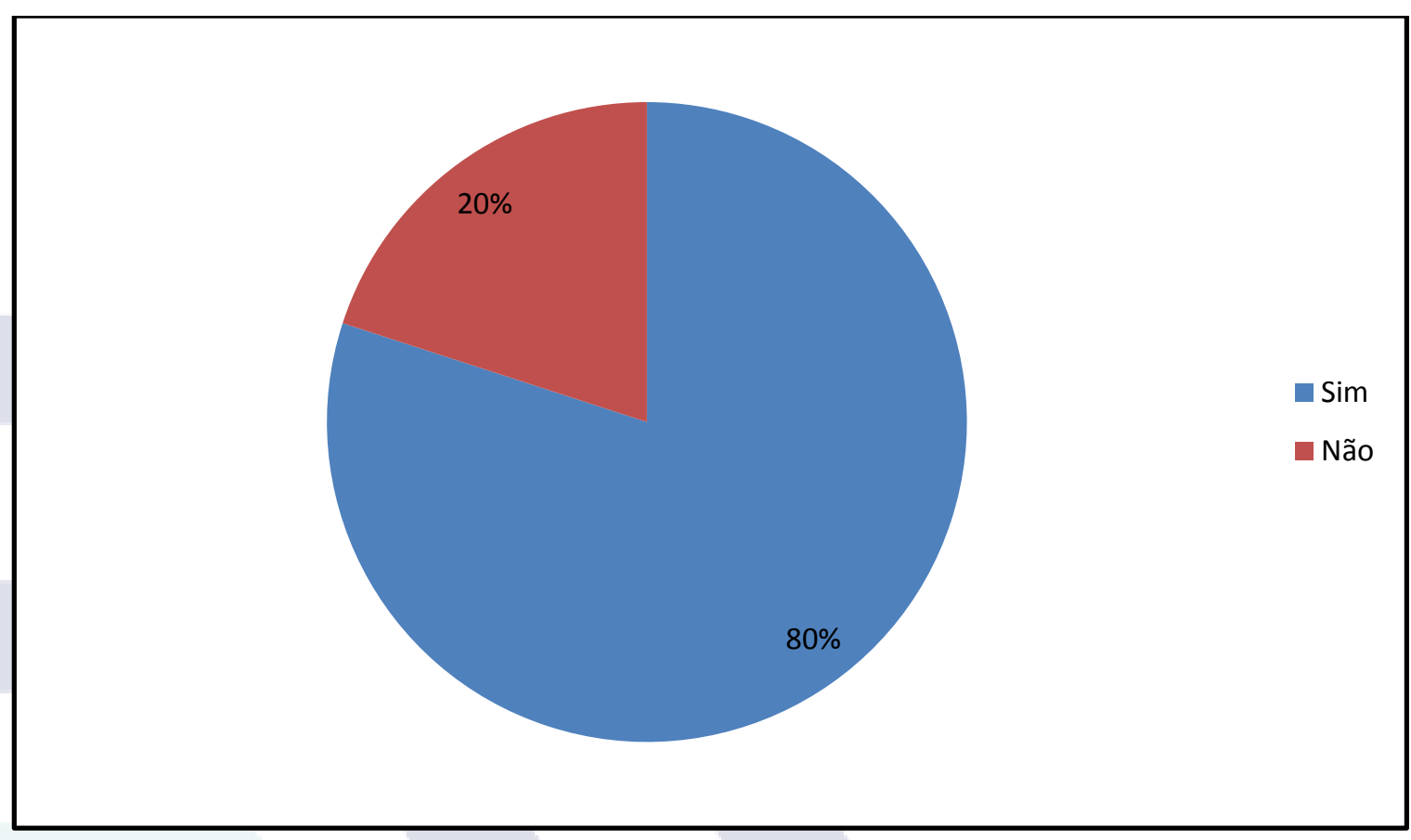

Fonte: Própria (2021).

No gráfico 4 é possível notar na sua grande maioria que a escola alvo da aplicação do questionário apresenta o uso do PPP exatamente como foi descrito na elaboração do documento. Isso não significa que todas as instituições seguem o que nele está escrito. Visto que, o PPP é um planejamento pedagógico anual que possuem flexibilidade para atualizações pertinentes sempre que necessário. Os dados obtidos nesse gráfico corroboram com Freitas (2013), onde o autor afirma que a elaboração desses documentos é de grande importância para a escola, pois, o mesmo serve como fio condutor e orientador de todas as suas determinantes ações, ao logo do ano letivo. No entanto, nem todas as instituições de ensino segue o que foi acordado durante a criação do PPP, algumas abandonam suas propostas pelo o trajeto que se é percorrido durante o ano, por apenas elaborarem o documento como forma comprobatória para fins da Lei de Diretrizes e Bases, no seu artigo 12, título IV. 
Gráfico 5 - Desenvolvimento do PPP da escola.

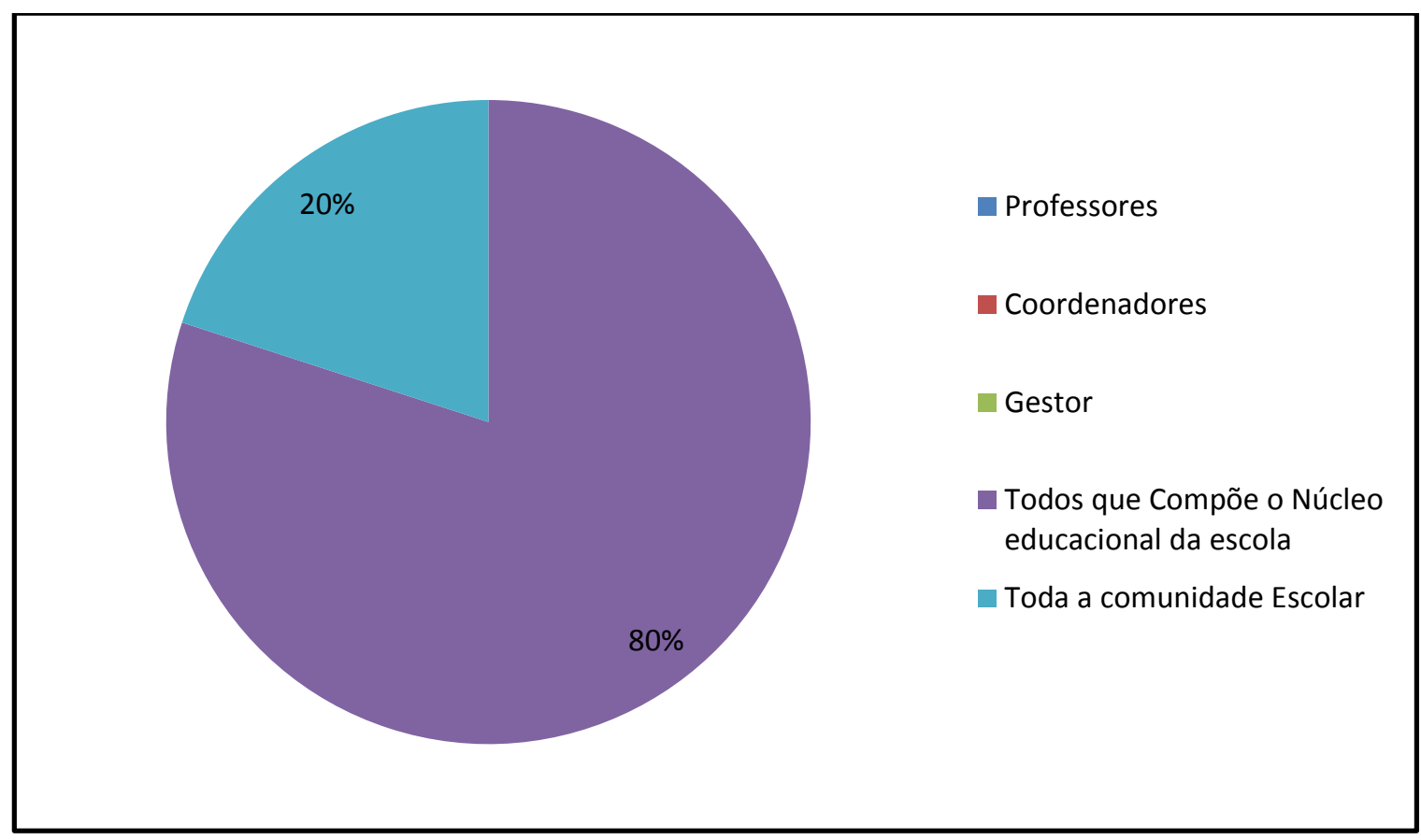

Fonte: Própria (2021)

No gráfico 5 é apresentado o percentual de desenvolvimento do PPP, o mesmo mostra que todos os envolvidos no núcleo educacional da escola colabora na elaboração deste documento. A contribuição de todos se faz necessária devido às diversas opiniões que irão contribuir no desenvolvimento do projeto, de forma significativa para a melhoria da comunidade escolar. Segundo Santos (2013) a contribuição dos pais também se faz necessária, pois, os mesmos podem não ter base teórica, mas, eles trarão angustias, medos e desejos sentidos em relação com a vida escolar dos filhos. Além desses aspectos, é provável que os pais possam transformar o olhar que a instituição, principalmente por meio dos docentes, tem em relação à prática pedagógica e a organização da escola. Esse olhar vindo de fora promove a observação de pontos que já se acomodaram aos olhos daqueles que convivem diariamente dentro daquele determinado espaço.

Comparando os dados levantados, entende-se que a introdução do Projeto Político Pedagógico - PPP na escola deve estar lado a lado com o trabalho em conjunto, para que as propostas consolidadas apresentem a devida fundamentação no desenvolvimento das práticas. 


\section{A IMPORTÂNCIA DA CONSTRUC̨ÃO DO PROJETO POLÍTICO}

\section{CONCLUSÕES}

Conclui-se que, o Projeto Político Pedagógico - PPP é um documento essencial no ambiente escolar, o mesmo aborda todos os componentes relacionados à estrutura geral da instituição, abrangendo todas as informações necessárias que estejam associadas à escola e a todos os seus membros. O questionário presente nessa pesquisa não contribuiu de forma significativa para o conhecimento geral do Projeto Político Pedagógico, a frente de um núcleo escolar responsável por a elaboração do mesmo.

Nesse contexto, é preciso que haja mais informações destinadas aos pais, para que os mesmos façam parte no momento da elaboração desse documento tão importante para a instituição, já que todos dependem e participam da mesma. Com a participação ativa é possível identificar os erros e os acertos que a escola possui e, por isso, todos precisam participar de forma consciente e assim colaborar para a melhoria do ambiente e a melhoria da vida social e individual. 


\section{REFERÊNCIAS}

Disponível em https://www.ibge.gov.br/cidades-e-estados/pe/salgueiro.html. Acesso em 28 jun.. 2021.

FERREIRA, A. V. S. Elementos de articulação: Missão, Visão, Valores e a identidade organizacional. Revista EDUICEP- ano 2016.

FREITAS, M. M. O. A Contribuição do Professor- coodenador na Elaboração e Execução do Projeto Político Pedagógico da Escola. Brasília, 2013, p. 46. Monografia (Especialização em Coordenação Pedagógica) - Universidade de Brasília.

FIGUEIREDO, M. B.; BOTELHO, A. F. A Relevância da Construção do PPP: seus tópicos e suas flexibilidades na prática profissional. Revista Eletrônica Itinerarius Reflectionis, Jataí, ISSN: 1807-9342, v. 14. N. 2. 2018, 07 jul. 2018, p. 1-21.

Disponível em: https://www.revistas.ufg.br/rir/article/view/51732. Acesso em 02 jul. 2021.

GUEDES, N. C. A importância do Projeto Político Pedagógico no processo de democratização da escola, Revista UACE, Fortaleza, 2021.

IBGE. IBGEcidades.ibge.gv.br. Atualizado em 2020. Disponível em: https://cidades .ibge.gov.br/brasil/pe/salgueiro/panorama, 2020. Acesso em 21 de jul. de 2021.

LEAL, R. X. Ideias Governamentais de uma Instituição Pública de Educação, Ciência e Tecnologia: Visão, Missão e Valores, Universidade Federal do Rio Grande do Norte - UFRN, Centro de Ciências Sociais Aplicadas - CCAS, Natal, 2017.

MACÊDO, J. A. A Importância do Planejamento Estratégico do Instituto Federal de Brasília no Cotidiano dos Servidores Técnicos Administrativos do Campus Samambaia. Brasília, 2016, p. 55. Certificado de Conclusão de Curso (Pós-Graduação Lato Sensu MBA em Gestão Pública) - Centro Universitário de Brasília - UNICEUB.

OLIVEIRA, C. M.; SILVA, D. G.; SOUZA, G. M. et al. A importância do gestor escolar no processo de inclusão dentro do Projeto Político Pedagógico - PPP, Manaus, SCIENTIA, Manaus, 2018.

PAIVA, A. M. Projeto Político Pedagógico e o engajamento no trabalho docente em uma escola municipal de educação infantil em Belo Horizonte - MG, Universidade Federal de Minas Gerais Faculdade de E ucação, Belo Hoizonte, 2019.

PASCHOAL, R. L. A Relação da Estrutura Física com o Processo Ensino Aprendizagem. Corumbá, 2016, p. 11. Trabalho de Conclusão de Curso - TCC (Curso de Especialização) Universidade Federal do Mato Grosso do Sul, UFMS.

RODRIGUES, E. M. A Desconstrução do Projeto Político-Pedagógico de Escolas Municipais de Cáceres- MT, Dissertação de Mestrado apresentada ao Programa de Pós-Graduação em Educação da Universidade do Estado de Mato Grosso, 2018.

SANTOS, J. G. S. O Projeto Político Pedagógico como Ferramenta da Gestão Escolar Democrática. Três Passos, 2013, p. 39. Monografia (Pós-Graduação a Distância em Gestão 


\section{A IMPORTÂNCIA DA CONSTRUC̣̃̃O DO PROJETO POLÍTICO}

Educacional) - Universidade Federal de Santa Maria - UFSM, RS.

SILVA, M. C. A. PROJETO POLÍTICO-PEDAGÓGICO: uma construção participativa na escola. Guarabira, 2011, p. 21. Trabalho de Conclusão de Curso - TCC (Licenciatura em Pedagogia) - Universidade Estadual da Paraíba.

TRINDADE, L. M.; PINTO, L. B. F.; CAVALCANTE, M. N.; ALMEIDA, R. S. PROJETO POLÍTICO PEDAGÓGICO: a gestão e a função social da escola para a comunidade. Revista Científica Semana Acadêmica. Fortaleza, ISSN 2236-6717, Ed. 69, vol. 1, 2015, 21 maio 2015, p. 1-16. 